\title{
Learning Through Service: Student Perceptions on Volunteering at Interprofessional Hepatitis B Student-run Clinics
}

\author{
Leslie C. Sheu • Patricia Zheng • Anabelle D. Coelho • \\ Lisa D. Lin - Patricia S. O'Sullivan • \\ Bridget C. O'Brien • Albert Y. Yu • Cindy J. Lai
}

Published online: 22 July 2010

(C) The Author(s) 2010. This article is published with open access at Springerlink.com

\begin{abstract}
Student-run clinics (SRCs) are widespread, but studies on their educational impact are limited. We surveyed preclinical medical, nursing, and pharmacy students about their experiences in a hepatitis B elective which provided opportunities to they could volunteer at hepatitis B screening and vaccination SRCs. Student responses revealed positive perceptions of the volunteer experience. Benefits included interacting with patients, developing clinical skills, providing service to disadvantaged populations, and collaborating with health professional peers. Students who participated in clinic reported enhanced skills compared to those who did not attend. SRCs play a valuable role in instilling positive attitudes and improving skills.
\end{abstract}

L. C. Sheu $(\varangle) \cdot$ P. Zheng $\cdot$ L. D. Lin

School of Medicine,

University of California,

505 Parnassus, M1078, Box 0120, San Francisco,

CA 94143, USA

e-mail: leslie.sheu@ucsf.edu

\section{A. D. Coelho}

School of Pharmacy,

University of California,

San Francisco, USA

P. S. O'Sullivan • B. C. O’Brien

University of California,

San Francisco, USA

P. S. O’Sullivan • B. C. O'Brien • C. J. Lai

Department of Medicine, University of California,

San Francisco, USA

\section{A. Y. Yu}

San Francisco Department of Public Health and Department of Family and Community Medicine, University of California,

San Francisco, USA
Keywords Student-run clinics · Service learning-interprofessional education $\cdot$ Health disparities education $\cdot$ Preclinical medical education $\cdot$ Volunteerism

\section{Introduction}

Service learning, defined as any experiential learning opportunity that combines clear educational goals with service to the community, has been broadly recognized as an effective curricular method to engage health professional students in patient advocacy and active learning while providing needed health services to underserved populations [1]. One method of providing such early service-learning opportunities is through student-run clinics (SRCs), which have flourished at many medical schools over the past few decades $[2,3]$. SRCs offer one way to support preclinical students' development of clinical skills, such as performing procedures, and professional skills, such as communicating effectively with patients and colleagues [3,4]. They may also increase students' desire to practice in similar settings in the future [5]. Furthermore, many SRCs involve students from various disciplines and most provide services for underserved populations, making them ideal settings for experiential interprofessional and health disparities education - two areas of medical education to which national accreditation agencies have called attention [2, 3, 6-8]. Despite the numerous benefits SRCs may have on medical education, reports on the value of SRCs from students' perspectives are lacking [2].

At the University of California, San Francisco (UCSF), preclinical students from the Schools of Medicine, Pharmacy, and Nursing established an interprofessional elective that consisted of required lectures and optional volunteer 
experiences at two SRCs focused on chronic hepatitis B virus (HBV) infection, an important local health disparity [9]. Chronic HBV infection disproportionately impacts Asian and Pacific Islanders (APIs), who make up 33\% of San Francisco County's population, compared to $5 \%$ nationally [10]. Untreated chronic HBV infection is the most common cause of cirrhosis and liver cancer worldwide, and APIs are six to 13 times more likely to die of liver cancer than their white counterparts $[11,12]$. While student-run HBV clinics have reported on the successful public health outcomes of their programs $[9,13,14]$, little is known about their impact on student participants.

In this study, we evaluated students' perceptions of the educational value of this interprofessional HBV elective, as well as its impact on students' interests in public health and health disparities, and attitudes on interprofessional collaboration.

\section{Materials and Methods}

\section{Description of Elective}

In November 2007, preclinical health professional students at UCSF established two monthly SRCs, one at Mount Zion Health Center, a UCSF-affiliated site, and the other at Chinatown Public Health Center, affiliated with the San Francisco Department of Public Health. At each of the clinics, which were open for 3 hours on two Saturday mornings per month and targeted towards the underserved API population through flyers, ads, and public service announcements, students participated in various clinical and administrative roles which allowed them to develop clinical and professional skills. Clinical skills included performing phlebotomy to screen for HBV infection, interpreting lab results of returning patients, and providing HBV vaccinations. Professional skills involved educating patients and working with peers and preceptors across health professional schools. Patient education consisted of discussion of HBV transmission modes, prevention, management, screening results, and complications of undetected $\mathrm{HBV}$, particularly liver failure and cancer. On average, eight to 12 student volunteers and five to eight student coordinators attended each clinic. Student volunteers across health professional schools were paired for clinical roles, and each pair saw an average of five to ten patients for screenings, discussing results, or follow-up vaccinations during a morning clinic.

These SRCs were accompanied by a prerequisite elective, which consisted of didactic lectures and hands-on training workshops. The goals of the program were twofold: (1) educate students about the HBV health disparity and equip them with skills to address the disparity through community education, screening, and vaccinations, and (2) offer services to improve community awareness about HBV and provide free screenings and low-cost vaccinations. The elective was publicized to students in all schools through emails, flyers, class announcements, and word-of-mouth.

\section{Measures}

Demographics We administered a 14-item survey to capture students' personal and participation demographics. These included number of sessions attended, reason for participating, and whether they had referred individuals to the clinic.

Reaction to Experience We developed 10 five-point Likertscaled questions on students' confidence in their clinical and professional skills (five items), interest in public health and health disparities (four items), and comfort working with other health professional students (one item) using the stem, "As a result of my participation in the HBV elective/clinics, I..." $(1=$ strongly disagree and $5=$ strongly agree). These items were piloted with students not eligible to participate to determine clarity and comprehension.

Perceptions of Value To elicit students' perceived value of the clinics, we had three open-ended questions for the students who chose to volunteer at the SRCs. These questions assessed students' perceptions of the value of (1) volunteering in the clinics, (2) working with a primarily immigrant and underserved population, and (3) working in an interprofessional clinic.

\section{Survey Subjects}

Study participants were first through third year students from the UCSF Schools of Medicine, Nursing, and Pharmacy who enrolled in the didactic HBV elective in Fall 2008-2009. Due to the limited enrollment of second and third year students and the potential influence of prior education on these students' HBV elective experience, only first years were included in comparative analyses to evaluate the effect of clinic participation. The students could have just enrolled in didactics or in didactics and clinic. The UCSF Institutional Review Board approved the study.

\section{Procedures}

Participants completed the survey anonymously through an on-line program. The survey was administered between June and July, 2009 after a year of participation in the clinic. 


\section{Data Analysis}

Qualitative content analysis was performed by three investigators (LS, AC, CL), who read all responses to the open-ended questions and independently generated lists of repeated content which were then grouped into larger themes. After consensus through discussion, a final list was used to independently code all responses to determine the frequency of each theme. Responses were multi-coded if they addressed multiple themes. Discrepancies in coding among the three raters were then discussed until consensus was reached. Only themes that were mentioned by five or more students were reported.

Quantitative analysis included generating descriptive statistics for students' self-reported confidence in clinical and professional skills, interest in public health and health disparities, and comfort working with students from other health professions. Student's $t$ tests were used to compare students who participated in at least one clinic after elective enrollment with students who did not participate in any clinics on the ten 'Reaction to Experience' items. Effect sizes were calculated to give an indication of the practical importance of differences between the two groups [15]. Due to the multiple tests, the $p$ value was set at 0.01 to control for type I error.

\section{Results}

Survey response rate was 85\% (117/137), including all eligible medical (15/15), most nursing (21/25), and most pharmacy (80/97) students (one respondent did not indicate school affiliation). Eighty-five percent of all students who completed the survey were first year students, with the remainder being second (9\%) and third (6\%) years. Sixty five percent of students identified themselves as API, and $42 \%$ reported fluency in at least one API language.

The most common reasons for enrollment in the elective were: (1) interest in the topic of $\operatorname{HBV}(68 \%)$, (2) desire to interact with patients $(61 \%)$, and (3) interest in volunteering $(57 \%)$. Eighty-seven respondents $(76 \%)$ reported having volunteered at one or more HBV clinics, attending an average of 2.8 clinics (SD 2.0). Fifty-six percent of students reported that as a result of the elective, they recommended HBV screening to family (37\%), friends $(30 \%)$, or other community members $(28 \%)$. Only the responses from first year students were used in the subsequent analyses.

\section{Qualitative analysis: Value of participating in hepatitis $B$ SRCs}

Nearly half $(47 \%)$ of the students who volunteered at clinics responded to one or more of the open-ended questions. Responses were coded for common themes (Tables 1, 2, and 3).

Value of Volunteering at Clinic When students were asked "What was valuable about volunteering at the clinics?" the most common themes in their responses were interacting with patients $(67 \%)$ and practicing procedural skills $(62 \%)$. Other themes included the value of outreach, working with the underserved API immigrant community, teamwork, and awareness about HBV.

Working with Underserved Immigrants In response to "Did the experience of working with a primarily immigrant and underserved population impact what you may do in your future practice? If so, how?" the majority ( $86 \%$ ) of students reported that working with a primarily immigrant and underserved population reinforced their commitment and interest in serving this population. Students also valued learning about the importance of effective communication (39\%) and reported a sense of personal fulfillment after working with this population $(32 \%)$.

Working with Students from Other Health Professions The majority $(85 \%)$ of students who responded to the question, "Did the clinics impact the way you view/work with students from other health professions? If so, how?" described the impact as one where they appreciated the opportunity for interprofessional collaboration (65\%), the chance to learn about the role of other health professionals $(46 \%)$, and to work as a team $(31 \%)$.

\section{Comparison between those who did and did not volunteer} in the clinic

Table 4 summarizes the comparison between first year students who did and did not volunteer for at least one clinic session. Students who attended clinic had statistically significantly higher self-reported confidence in clinical, interpretation, and education skills.

\section{Discussion}

In our study, we found that although interest in the topic of $\mathrm{HBV}$ was the most commonly cited reason for enrolling in the HBV elective, the greatest impact of the clinical experience was in offering real patient encounters and opportunities to practice clinical skills-opportunities not available in the classroom. Students who volunteered at HBV SRCs also valued working with the underserved API immigrant community and working with students from other professional schools. These findings build upon a 
Table 1 Themes describing the value of volunteering at HBV student-run clinics $(n=39)$

\begin{tabular}{|c|c|}
\hline Theme & Sample comments \\
\hline 1. Patient interaction $(n=26,67 \%)$ & $\begin{array}{l}\text { "The most valuable thing about volunteering at clinics is helping the patients." } \\
\text { "Patient education was very valuable because I was often dispelling myths that patients } \\
\text { have heard about the disease and it's great that we can give them accurate information." }\end{array}$ \\
\hline 2. Clinical skills $(n=24,62 \%)$ & "It's more valuable to actually practice something, than to merely learn about it." \\
\hline 3. Outreach $(n=11,28 \%)$ & "Most valuable is knowing that we have an impact on an individual and community level." \\
\hline $\begin{array}{l}\text { 4. Working with underserved/API immigrant } \\
\text { community }(n=8,21 \%)\end{array}$ & $\begin{array}{l}\text { "It was helpful working with the API population because I previously had not." } \\
\text { "I thought it was great to be able to perform services for the underserved." }\end{array}$ \\
\hline 5. Teamwork $(n=8,21 \%)$ & $\begin{array}{l}\text { "Everyone works together and [is] willing to work together. Preceptors are } \\
\text { easy to talk to and provide support." } \\
\text { "It was nice to work with students from other schools. This is one of the few } \\
\text { opportunities we get to do this." }\end{array}$ \\
\hline 6. HBV knowledge and awareness $(n=5,13 \%)$ & $\begin{array}{l}\text { "I learned a lot about Hep B. Before this elective and volunteer experience I } \\
\text { had little idea how prevalent and carcinogenic the virus was. I liked being a } \\
\text { part of the effort to eradicate San Francisco of Hep B." }\end{array}$ \\
\hline
\end{tabular}

previous report that SRCs providing services to the homeless population contributed to social awareness, compassion and empathy, teamwork, and confidence building-four themes that arose from their student reflections after volunteering [4].

Nearly two thirds of the students identified themselves as API, which may be due to self-selection rooted in students' interest to learn about and reduce health disparities for patients of similar ethnic and racial backgrounds. Student responses suggest that HBV SRCs may have positively influenced their attitudes about health disparities and working with the underserved API immigrant population, which is encouraging given the shortage of medical personnel working with underserved populations and the reported difficulties facing API immigrants in accessing healthcare $[16,17]$. By increasing the pool of healthcare providers attuned to providing care to API immigrants, HBV SRCs address barriers to $\mathrm{HBV}$ screening, such as poor awareness about HBV within API communities and poor provider understanding of screening guidelines [18, 19].

Another highlight of our HBV SRCs was its emphasis on interprofessional collaboration. One recent report suggests that student leadership is critical to the success of interprofessional education, as it enhances students' willingness to collaborate and fosters continuity [20]. In many existing interprofessional SRCs, students from different health professions come together to provide different services in their fields of expertise [2]. However, at our HBV clinics, medical, nursing, and pharmacy students worked alongside one another performing the same tasks, enhancing opportunities for shared learning and collaboration. In students' open-ended responses, SRC participants valued working with other health professionals in this unique collaborative environment, where the common ground and identical responsibilities allowed for

Table 2 Common themes on impact of working with immigrant and underserved patients $(n=28)$

Theme Sample comments

1. Commitment/Interest $(n=24,86 \%)$

Outreach $(n=5,18 \%)$

Awareness $(n=6,21 \%)$

2. Patient communication $(n=11,39 \%)$

Language barrier $(n=9,32 \%)$

3. Personal fulfillment $(n=9,32 \%)$
"I've always wanted to work in the community, but this experience help to solidify the need for health care professionals and the medically indigent community."

"I feel that we need to do more outreach to the underserved community."

"I think that it made me more aware of the need to serve these populations and even if I don't pursue a practice specializing in this I will definitely try to spend some of my time as a professional helping out underserved communities."

"It has helped me to be more patient and more dedicated to making sure the patients understand what is taking place at their visit."

"It has helped me understand the many critical factors in working with immigrant/underserved populations, including providing appropriate translation services and CLEAR linguistically \& culturally appropriate info."

"It was fulfilling working with the underserved population. It felt good to provide this service to them and you can tell that they are very thankful for it as well." 
Table 3 Common themes on impact of working with other health professional students $(n=26)$

\begin{tabular}{ll}
\hline Theme & $\begin{array}{c}\text { Sample comments } \\
\text { 1. Opportunity to work with other health professional students }(n=17,65 \%)\end{array} \begin{array}{r}\text { "It was the only opportunity that I had during school } \\
\text { this year to participate in a meaningful interdisciplinary } \\
\text { experience with other students." } \\
\text { "It is nice to hear about what each other does/will } \\
\text { be doing, because we will eventually work together } \\
\text { in the future as professionals." } \\
\text { "More of our education should be integrated, so that } \\
\text { partnership and teamwork happens more naturally." } \\
\text { 3. Teamwork/Collaboration }(n=12,46 \%)\end{array} \begin{array}{l}\text { "It was a positive experience working with other } \\
\text { health professions. They were really friendly } \\
\text { and easy to work with." }\end{array}$ \\
\hline
\end{tabular}

more opportunities for interprofessional discussions about future professional roles. This interprofessional approach may be important in the context of addressing healthcare disparities such as HBV screening, prevention, and management. As institutions and national accreditation agencies place greater emphasis on teamwork among the different disciplines to improve patient care [7, 21-23], educators may consider utilizing SRCs to provide a conducive environment to promote this interaction early in health professional education. Given that students' attitudes toward interprofessional learning are most positive when they first enter their training, and tend to decline over time without appropriate intervention, such early interprofessional experiences may be critical to promoting effective communication across health disciplines [24, 25].

Our quantitative results support the findings from students' open-ended responses. All students, regardless of whether they volunteered in the SRC, reported a strong interest in public health and awareness of health disparities and favorable attitudes toward working with other professions. In comparing elective students who volunteered at SRCs versus those who did not, there was a statistically significant difference in students' self-reported confidence in clinical and professional skills, which corroborates with the finding that SRC participants gain valuable practical and hands-on experiences. However, while SRC participants had higher confidence in these domains than those who did not participate, the level of confidence was not high, suggesting that although direct patient care experiences were important in improving students' confidence in their clinical skills, preclinical experience is still limited and students at all levels need iterative clinical opportunities to gain greater confidence $[26,27]$.

This study had several limitations. First, although we had an overall excellent survey response rate, only $47 \%$ of the students who attended SRCs provided responses to the

Table 4 Comparison of scores between clinic participants and non-participants on confidence and skills items at end of the elective

\begin{tabular}{|c|c|c|c|c|}
\hline Domain & $\begin{array}{c}\text { Didactic only } \\
\text { (no clinics) } \\
n=16 \\
\text { Mean (SD) }\end{array}$ & $\begin{array}{l}\text { Didactic } \\
\text { and } \geq 1 \text { clinic } \\
n=83 \\
\text { Mean (SD) }\end{array}$ & Effect size & $P$ value \\
\hline I feel confident in my ability to perform phlebotomy & $2.33(1.35)$ & $4.36(0.83)$ & 0.95 & $<0.001$ \\
\hline I feel confident in my ability to perform hepatitis B vaccinations & $2.73(1.33)$ & $4.36(0.83)$ & 1.49 & $<0.001$ \\
\hline I feel confident in my ability to interpret hepatitis B lab results & $2.07(1.21)$ & $3.38(1.16)$ & 1.05 & $<0.001$ \\
\hline I feel confident in my ability to educate patients about hepatitis B infection & $2.80(1.01)$ & $3.45(1.06)$ & 0.79 & $<0.001$ \\
\hline I feel confident in my ability to explain hepatitis B lab results to patients & $2.47(1.46)$ & $3.28(1.06)$ & 0.70 & 0.012 \\
\hline $\begin{array}{l}\text { My interest in working with the Asian and Pacific Islander (API) immigrant } \\
\text { community has increased }\end{array}$ & $3.07(0.96)$ & $3.77(1.00)$ & 0.68 & 0.014 \\
\hline My interest in public health has increased & $3.67(0.90)$ & $3.99(0.92)$ & 0.35 & 0.21 \\
\hline $\begin{array}{l}\text { My interest in working with underserved populations as } \\
\text { part of my career has increased }\end{array}$ & $3.54(0.92)$ & $3.95(0.95)$ & 0.44 & 0.12 \\
\hline My awareness of health disparities in API populations has increased & $3.79(0.89)$ & $4.00(0.85)$ & 0.25 & 0.39 \\
\hline $\begin{array}{l}\text { I feel comfortable working in a team or partnership with students } \\
\text { from other health professions in a clinical setting }\end{array}$ & $4.04(0.81)$ & $4.29(0.79)$ & 0.31 & 0.16 \\
\hline
\end{tabular}

Likert scores for confidence, interest, and comfort ranged from low (1) to high (5) 
optional open-ended questions, and thus the themes generated from the qualitative analysis may not be representative of the entire group. Secondly, students' baseline skills confidence, interprofessional attitudes, and public health and health disparities interests were not assessed, so we cannot be certain that the differences in scores between SRC participants and non-participants were due to attending clinics. Although the topic of HBV was not officially a part of the first year required curricula for any of the health professional schools, students may have had other experiences outside of school which influenced their responses. We attempted to clarify this effect by asking specifically about the HBV elective's effect on students within each question stem. Lastly, the quantitative results were not derived using validated survey instruments and were broad in scope, so while the results are consistent with students' open-ended responses, no definitive conclusions can be drawn from the quantitative results alone. Although these results begin to elucidate students' perspectives on SRCs, more robust assessments on the educational impact of SRCs using validated survey instruments and including baseline data prior to involvement are needed.

Our findings suggest that preclinical students value service learning in the setting of interprofessional SRCs for many reasons. The reasons given included developing patient communication and procedural skills to nurturing positive attitudes toward interprofessional collaboration. Given that most preclinical health professional curricula are primarily classroom based [28], SRCs may be one model for augmenting students' classroom knowledge through direct community involvement.

Open Access This article is distributed under the terms of the Creative Commons Attribution Noncommercial License which permits any noncommercial use, distribution, and reproduction in any medium, provided the original author(s) and source are credited.

\section{References}

1. Eckenfels EJ (2009) The purpose of service learning. Fam Med 41 (9):659-662

2. Meah YS, Smith EL, Thomas DC (2009) Student-run health clinic: novel arena to educate medical students on systems-based practice. Mt Sinai J Med 76(4):344-356

3. Simpson SA, Long JA (2007) Medical student-run health clinics: important contributors to patient care and medical education. J Gen Intern Med 22(3):352-356

4. Clark DL, Melillo A, Wallace D et al (2003) A multidisciplinary, learner-centered, student-run clinic for the homeless. Fam Med 35 (6):394-397

5. Campos-Outcalt DE (1985) Specialties chosen by medical students who participated in a student-run, community-based free clinic. Am J Prev Med 1(4):50-51

6. Smedley BD, Stith AY, Nelson AR (eds), Institute of Medicine (2002) Unequal treatment: confronting racial and ethnic disparities in health care. Washington, DC: National Academies Press
7. Greiner AC, Knebel E (eds), Institute of Medicine (2000) Health professions education: a bridge to quality. Washington, DC: National Academy Press

8. Functions and structure of a medical school: standards for accreditation of medical education programs leading to the MD degree (2008) Available at www.lcme.org. Accessed May 14, 2010.

9. Sheu LC, Toy BC, Kwahk E et al (2010) A model for interprofessional health disparities education: student-led curriculum on chronic hepatitis B infection. J Gen Intern Med 25(2):S140-S145

10. US Census Bureau (2008) Population estimates, population division. Available at http://factfinder.census.gov. Accessed May 14, 2010.

11. Juon H, Strong C, Oh TH et al (2008) Public health model for prevention of liver cancer among Asian Americans. J Community Health 33:199-205

12. Parkin DM (2006) The global health burden of infection-associated cancers in the year 2002. Int J Cancer 118(12):3030-3044

13. Hsu LD, DeJong W, Hsia R, Chang M, Ryou M, Yeh E (2003) Student leadership in public health advocacy: lessons learned from the hepatitis B initiative. Am J Public Health 93(8):1250-1252

14. Chang ET, Sue E, Zola J, So SK (2009) 3 For life: a model pilot program to prevent hepatitis B virus infection and liver cancer in Asian and Pacific Islander Americans. Am J Health Promot 23 (3):176-181

15. Hojat M, Xu G (2004) A visitor's guide to effect sizes: statistical significance versus practical (clinical) importance of research findings. Adv Health Sci Educ 9(3):241-249

16. Rosenblatt RA, Andrilla CHA, Curtin T, Hart LG (2006) Shortages of medical personnel at community health centers: implications for planned expansion. JAMA 295(9):1042-1049

17. Ngo-Metzger Q, Massagli MP, Clarridge BR et al (2003) Linguistic and cultural barriers to care: perspectives of Chinese and Vietnamese immigrants. J Gen Intern Med 18:44-52

18. Nguyen TT, Taylor V, Chen MS Jr, Bastani R, Maxwell AE, McPhee SJ (2007) Hepatitis B awareness, knowledge, and screening among Asian Americans. J Cancer Educ 22(4):266-272

19. Lai CJ, Nguyen TT, Hwang J et al (2007) Provider knowledge and practice regarding hepatitis $\mathrm{B}$ screening in Chinese-speaking patients. J Cancer Educ 22(1):37-41

20. Hoffman SJ, Rosenfield D, Gilbert JHV, Oandasan IF (2008) Student leadership in interprofessional education: benefits, challenges and implications for educators, researchers and policymakers. Med Educ 42:654-661

21. Association of American Medical Colleges (2009) Medical School Graduation Questionnaire All Schools Report. Washington, 2009. Available at http://www.aamc.org/data/gq/allschoolsreports/start. htm. Accessed May 14, 2010.

22. Reeves S, Zwarenstein M, Goldman J et al (2008) Interprofessional education: effects on professional practice and healthcare outcomes. Cochrane Database Syst Rev 1:CD002213

23. Hammick M, Freeth D, Koppel I et al (2007) A best evidence systematic review of interprofessional education: BEME guide no. 9. Med Teach 29(8):735-751

24. Coster S, Norma I, Murrells T et al (2008) Interprofessional attitudes amongst undergraduate students in health professions: a longitudinal questionnaire survey. Int J Nurs Stud 45(11):1667-1681

25. Hind M, Norman I, Cooper S et al (2003) Interprofessional perceptions of healthcare students. J Interprof Care 17(1):21-34

26. Brandling-Bennett HA, Capaldi LA, Gilchrest BA et al (2006) Improving skin cancer prevention and detection education in US medical schools. Arch Dermatol 142:524-526

27. Issenberg SB, McGaghie WC, Hart IR (1999) Simulation technology for healthcare professional skills training and assessment. JAMA 282(9):861-866

28. Parsi K, List J (2008) Preparing medical students for the world: service learning and global health justice. Medscape J Med 10 (11):268 